\title{
Therapeutic Potency of Citrus Limon (L) Burm. F. (Lemon) Peel Extract Against Some Disease Causing Microorganisms
}

\author{
Ewansiha, J.U**1, ${ }^{\text {., Garba, S.A }}{ }^{1}$, Galadima, $M^{1}$, Daniyan, S.Y ${ }^{1}$, Busari, M. B ${ }^{3}$ \\ ${ }^{1}$ Department of Microbiology, Federal University of technology Minna, Niger State Nigeria \\ ${ }^{1,2}$ Department of Microbiology, Federal University of Technology, Yola, Adamawa State, Nigeria \\ ${ }^{3}$ Centre for Genetic Engineering and Biotechnology/Global Institute for Bioexploration, Federal \\ University of Technology, Minna, Niger State, Nigeria.
}

\begin{abstract}
The therapeutic potency of Citrus limon L (lemon) peel extract was investigated using reflux extraction, agar well diffusion and dilution methods. In the extraction result, ethanol extract had the highest yield (7.64\%) followed closely by ethyl acetate extract (6.68\%) while aqueous extract had $3.83 \%$. There was no hexane extract. 11 phytochemical constituent viz: saponins, alkaloids, flavonoids, anthraquinons, volatile oils, resins, phenols cardiac glycosides, tannins, terpenes, and steroids were present in the various extracts. Ethyl acetate and ethanol extract were more active against the test organisms with inhibition zone diameter (IZD) of $7.66 \pm 0.33 \mathrm{~mm}$ as the lowest against $S$ paratyphi $C$ to $12.00 \pm 0.57 \mathrm{~mm}$ against $S$ paratyphi $B$ while $7.00 \pm 0.00 \mathrm{~mm}$ was recorded for aqueous extract against 3 different organisms. $S$ paratyphi $B$ and Streptococcus pyogenes were more susceptible to the peel extract as a lower MIC and corresponding $M B C$ of $12.5 \mathrm{mg} / \mathrm{ml}$ and $50 \mathrm{mg} / \mathrm{ml}$ respectively was recorded against the two organisms while $S$ paratyphi $C$ and Salmonella typhi were the most resistant organisms with $M B C$ above $100 \mathrm{mg} / \mathrm{ml}$ recorded against both organisms. The result of this study reveals that the peel extract of Citrus limon possess antimicrobial potency against the test organisms and therefore can be further purified to develop drug for the treatment and control of infections caused by these pathogens.
\end{abstract}

Keywords: Peel, molecular identification, flavonoids, Citrus limon, Reflux extraction.

\section{INTRODUCTION}

Medicinal herbs have gained much attention and awareness as alternative drugs for the treatment or prevention of health related disorders (Agyare et al., 2009). The applications of medicinal plants all over the world predates the introduction of antibiotics and other modern drugs into the African continent. Herbal medicines have been enormously used as part or integral of primary health care in some Nations in the world (Akinyemi et al., 2005). For the past few decades, many plants have been screened for biological, pharmacological and toxicological properties by researchers. All these steps are continually being taken to study the intrinsic worth of traditional medicine in the light of modern science with such screening aimed at adopting effectively beneficial medical practice thereby discouraging harmful approaches (Abere et al., 2010). Note worthily, components of herbs serve as starting materials for a number of old and new pharmaceutical products and About $25 \%$ of modern pharmaceutical drugs have been reported as having botanical origins.

Medicinal plants have therefore been described as one in which one or more of its organs contain substances that can be used for therapeutic purposes (Rios and Recio, 2005). It may be in the form of vegetable drugs which may either be organized (material which possess a cellular structure e.g. Leaf, bark petal, flower, stem, root, etc.) or unorganized drugs (a cellular structural medicinal agent such as gums, balsams and Latex). Such plant materials may be utilized in the form of decoctions in cold water or warm water, concoctions, preparations of soups, drinks etc. made fully from many ingredients. They can also be used as infusions often made by pouring water on a specified plant material and allowing the mixture to stand for about 15 minutes (Plant Database, 2008). An estimated $80 \%$ of the world population today rely entirely on local medicines made almost exclusively from plants (Jonas et al., 2003). It has been assumed that between 35, 000 and 70,000 different plant species have been used as medicines by various people of the world and as western medicine continues to be unaffordable or in many instances inappropriate, this pattern of dependence on local 
herbal cure is set to rise (UNESCO, 1994). Plant source of medication is natural while in contrast cure provided by the chemically synthesized medicines have side effects on our body. Excessive use of drugs has also caused resistance in bacteria over periods of time and use (Shivendu et al., 2012). These drugs also affect the natural microflora of our body which are beneficial to our metabolism.

Citrus limon is an evergreen plant that is native to Asia. It is popularly utilized for its juice, pulp \& also the peels. It is used in many parts of the world and some folks add its juice to black tea while others apply it in cooking dishes because its juice provides a unique sour taste. It is rich in citric acid with a pH range of 2.5 to 3 . Lemon is used to make lemonades, cocktails, beverages, etc. It is also a plant of interest because of its medicinal value as reported by (Jitu et al., 2011). Its exhibits antimicrobial properties thus, its potential to inhibit microbial growth should be explored. Since it is easily available and common in use, extracts from it can serve as medicines for the treatment of some infections. Reports from local traditional marketers and consumers indicate that lemon fruit in concoction with other herbal plants is used for the treatment of typhoid fever and upper respiratory infections. The aim of this present study is to verify and authenticate the claims by the local user which will be achieved by subjecting the peel of Citrus fruit extract to antimicrobial screening and phytochemical analysis.

\section{Materials AND Methods}

\subsection{Materials}

\subsubsection{Equipment, Apparatus and Reagents}

The materials used for this research includes standard laboratory equipment's, glass wares and reagents purchased from the Scientific Equipment and Development Institute and Nahson Laboratory, Minna, Nigeria. All chemicals and solvents were of analytical reagent grade and requires no further purification.

\subsubsection{Identity of Test Organisms}

\section{Gram Staining}

An overnight culture of the test organisms were Gram stained, Gram positive and Gram negative organisms were recorded. A control smear of known Gram positive organism (Staphylococcus aureus) and a known gram negative organism (Escherichia coli) was stained simultaneously to confirm the accuracy of the procedure.

\subsubsection{Molecular Identification}

The test organisms include species of Salmonella enterica, Klebsiella pneumonia, Streptococcus pneumonia and Streptococcus pyogenes. They were all obtained from stock cultures in the Microbiology Laboratory of the Federal University of Technology, Minna, Nigeria. The organism's identity were molecularly authenticated according to Promega Protocol (Technical Manual \#TM050) (www.promega.com) and their identity and accession numbers were determined by BLAST (comparison of the extracted GENE sequence with the known sequence from the GENE bank) (www.ncbi.nlm.nih.gov).

\subsubsection{Plant Materials}

The plant under study is Citrus limon, belonging to the Rutaceae (Rue Family, Citrus Family). It grows as small thorny trees which reaches a height of 10 to 20 feet and can survive eve in drought but mostly available during the dry season. The part of the plant used was the peel of the fruit Plate I.

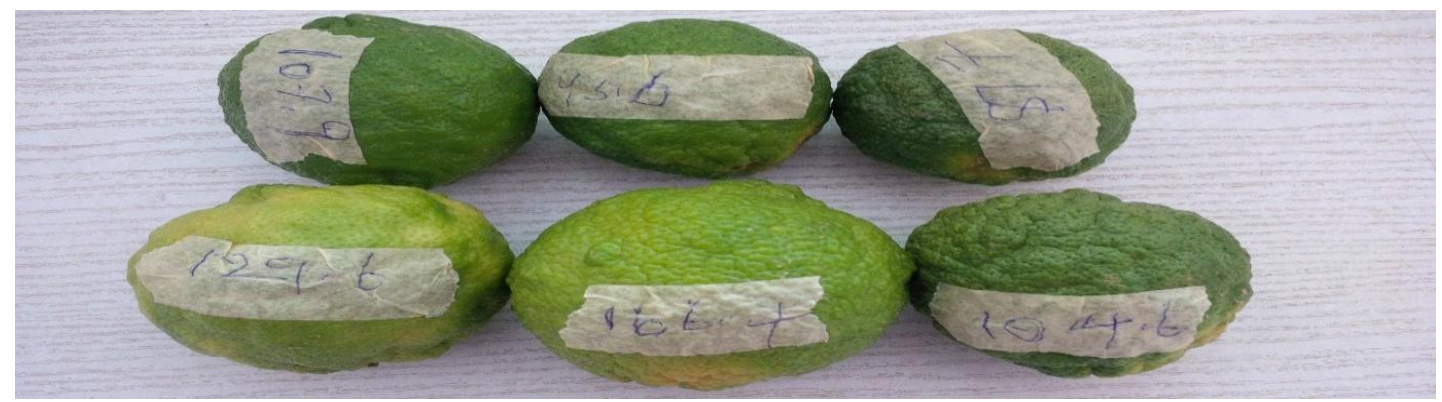

PlateI. Citrus Limon fruit 


\subsection{Methods}

\subsubsection{Collection and Processing of Plant Materials}

The fruit if Citrus limon was collected in September during the dry season, it was identified by local medicinal drug marketers in Gwari market, Niger state, Nigeria while authentication was done at the herbarium department of The National Institute of Pharmaceutical Research and Development by Dr Ugbabe Grace E where Sample was deposited and Voucher number (NIPRD/H/6780) was assigned. The peels were gently removed with care without the pulp using $70 \%$ methanol-sterilized kitchen knife. The peels were dried under shade for almost two months to obtain a constant weight. The dried peels were then pulverised using a milling machine (Lab world NAVBHART, with serial No. R66902 by MOTOR MFG, CO. Mumbai-India) and the pulverized plant samples were sieved with a $150 \mu \mathrm{m}$ pore size filter to obtain a fine powdered-like texture. The dried pulverised peels were weighed, labelled as sample A and kept in a dried container at room temperature for further use.

\subsubsection{Extraction}

The plant peel sample (A) was extracted successively by reflux using four different solvents in increasing order of their polarity. The extraction begins with the use of n-hexane (with polarity index of 0.0 'p) at a ratio of 1:4 (sample: solvent), after 2 hours of refluxing, the mixture was filtered through muslin cloth and the filtrate was evaporated in a rotary evaporator to a semisolid texture which was freeze-dried using LGJ-10 lyophilized at a temperature of $-30^{\circ} \mathrm{C}$ to a fine powder which was stored in an air-tight amber bottle and kept in the refrigerator at $4^{0} \mathrm{C}$ for further analysis. The residue (marc) obtained after filtration with muslin cloth was next weighed and extracted by reflux using ethyl acetate (polarity index of 4.4'p) also at a ratio of 1:4 (sample : solvent). It was next filtered and processed as above. This same process was also applied using methanol (polarity index of 5.2'p) while decoction method was applied for the water extract.

\subsubsection{Decoction}

In this process, the marc obtained after extraction with the organic solvents was transferred into a round-bottom flask containing a starting ratio of crude marc to water (polarity index of 10.2'p) of 1:16; the volume was then brought down to $1: 4$ its original volume by boiling during the extraction procedure for 2 hours; it was then cooled and filtered through a whatman filter paper with pore size of $20 \mu$. This procedure is suitable for extracting water-soluble, heat stable constituents. The solvent in the filtrates (containing the solvent and plant extract) was then evaporated in a rotary evaporator and a semi-solid extract was obtained. The semi-solid extract was then freeze-dried in a lyophilizer to a powdered form and the weight was measured and recorded. The powdered extract was transferred into universal containers and stored in refrigerator at $4.44^{\circ} \mathrm{C}(40 \mathrm{~F})$ until required for further use (Sukhdev et al., 2008).

The percentage yield of the crude extracts were determined using the equation below.

Percentage yield $=\frac{\text { weight of extract or Oil_ }}{\text { Weight of dry plant material }} \times \frac{100}{1}$

\section{Phytochemical Analysis}

Phytochemical analysis of the plant extract was done according to the method of Edeoga et al. (2005) and Sofowora.(2003).11different phytochemicals were analysed for, these includes steroids, alkaloids, cardiac glycosides, volatile oil, phenol, flavonoids, saponins, tannins, Anthraquinone, terpenoids, and glycosides.

\subsection{Test for Alkaloids}

Ten grams $(10 \mathrm{~g})$ of the leaf extracts were transferred into $500 \mathrm{ml}$ capacity beaker and a strong solution of ammonia was added in a quantity just sufficient to moisten the mixture and allowed stand for 10minutes after thorough mixing. A mixture of chloroform and ethanol solution in the ratio 1:1 was added just to soak and suspend the extract. The mixtures were allowed to stand for 20minutes with occasional stirring with the aid of a glass rod stirrer. The mixtures were next filtered through a plug of cotton wool and washed twice with $2 \mathrm{ml}$ Chloroform. The bulk filtrate was concentrated to dryness without overheating. The residue were cooled and dissolved in $5 \mathrm{ml}$ Chloroform only. The chloroform 
solution was transferred to a small separating tunnel and shaken with $3 \mathrm{ml}$ of dilute sulphuric acid. The two layers were allowed to separate, while the chloroform lower layer was drained off and discarded. Three millilitres of chloroform was further added and shaken, drained off and discarded until upper acid layer was colourless. The acid layer was made completely alkaline with strong ammonia solution; it was next tested with an indicator paper. The extracts with $3 \mathrm{ml}$ of chloroform were evaporated to dryness. The residue was dissolved in $3 \mathrm{ml}$ of ethanol and the following tests were carried out after neutralizing with dilute sulphuric acid. Little amounts of the ethanol solution were added in drop-wise manner to a few drops of Mayer's solution (potassium mercuric iodine) test tubes. The presence of precipitate in the above indicates the presence of alkaloids (Evans et al., 2007).

\subsection{Test for Flavonoids}

Five millilitre $(5 \mathrm{ml})$ of dilute ammonia was added to the aqueous portion of the extract followed by concentrated sulphuric acid $(1 \mathrm{ml})$. A yellow coloration that disappears on standing indicates the presence of flavonoids.

\subsection{Test for Phenols}

One millilitre $(1 \mathrm{ml})$ of crude extract and Iron (III) chloride were mixed and vortexed for 2 minutes. The Formation of a deep bluish green colouration is indicative of the presence of phenols.

\subsection{Test for Saponins}

Two grams $(2 \mathrm{~g})$ of the powdered sample was heated to boil in $20 \mathrm{ml}$ of distilled water and then filtered. $10 \mathrm{ml}$ of the filtrate was next vortexed with $5 \mathrm{ml}$ of distilled water and shaken vigorously for the generation of persistent froth. The frothing was mixed with 3 drops of olive oil and re-shaken again vigorously, it was then observed for the formation of emulsion.

\subsection{Test for Cardiac Glycosides (Keller-Killani test)}

Five $(5 \mathrm{ml})$ of each extracts was treated with $2 \mathrm{ml}$ of glacial acetic acid containing one drop of ferric chloride solution and was further treated with $1 \mathrm{ml}$ of concentrated sulphuric acid. A brown ring of the interface indicates a deoxysugar characteristic of cardenolides. A violet ring may appear below the brown ring, while in the acetic acid layer, a greenish ring may form just gradually throughout thin layer indicative of the presence of cardiac glycosides according to Trease, and Evans, (2002).

\subsection{Test for Tannins}

Five $(0.5 \mathrm{~g})$ of the dried plant samples was heated to boil in $20 \mathrm{ml}$ of distilled water in a test tube and the mixture was filtered. A few drops of $0.1 \%$ ferric chloride was added dropwise and it was observed for brownish green or a blue-black coloration, indicative of tannins.

\subsection{Test for Terpenoids (Salkowski test)}

Five $(5 \mathrm{ml})$ of each extract was mixed in $2 \mathrm{ml}$ of chloroform, and about $3 \mathrm{ml}$ of concentrated H2S04 was carefully added to form a layer. A reddish brown coloration of the inter face was formed to show positive results for the presence of terpenoids.

\subsection{Test for Steroids}

To $2 \mathrm{ml}$ of acetic anhydride was added to $0.5 \mathrm{~g}$ of each sample with $2 \mathrm{ml} \mathrm{H}_{2} \mathrm{SO}_{4}$. The colour changed from violet to blue or green in some samples indicating the presence of steroids.

\subsection{Test for Anthraquinone}

Borntrager's test - To show the presence of free Anthraquinone, $0.5 \mathrm{~g}$ of the powdered leaf samples were taken in dry test tubes. Ten millilitres of Chloroform were added to each and the mixtures was shaken for 5 minutes. It was next filtered and an equal volume of ammonia solution added to the filtrate and thoroughly shaken. A bright pink colour in the upper aqueous layer indicates the presence of free anthraquinones.

\subsection{Test for Volatile Oils}

Volatile oils are characterized by their odour, oil-like appearance and ability to volatilize at room temperature. The plant materials were distilled with water by steam distillation and the distillates were collected in a graduated tube. The aqueous portion which separates automatically was returned to the distillation flask. The formation of emulsion which floats on top of the aqueous phase owing to its low density is indicative of the presence of volatile oils. 


\subsection{Test for Resins}

Solutions of $5 \mathrm{ml} \mathrm{n}$-hexane were made using $0.1 \mathrm{~g}$ of powdered leaf samples of Citrus limon and was well labelled. An equal volume of copper acetate solution was added and shaken vigorously then allowed to separate. A green colour indicates the presence of resins.

\section{Antimicrobial Sensitivity Test}

\subsection{Standardization of Inoculum}

The test organisms were standardized according to the method of CLSI, (2012) by transferring $0.2 \mathrm{ml}$ of overnight culture of the test organism into a freshly prepared nutrient broth $(20 \mathrm{ml})$ and the culture was incubated for 3 to 5 minutes to give a turbidity equivalent to $10^{6} \mathrm{cfu} / \mathrm{ml}$. This was used to inoculate the media for the determination of antimicrobial activity and minimum inhibitory concentration.

\subsection{Preparation of Extract}

A single dose concentration of $40 \mathrm{mg} / \mathrm{ml}$ was prepared by dissolving $200 \mathrm{mg}$ of the peel extract in $5 \mathrm{ml}$ of $20 \%$ DMSO while for the standard antibiotics used for the positive control, $0.1 \mathrm{~g}$ was weighed and dissolved in $100 \mathrm{ml}$ of distilled water to give $1 \mathrm{mg} / \mathrm{ml}$.

\subsection{Screening Of Extracts for Antimicrobial Activity}

Antimicrobial susceptibility screening was done using agar-diffusion method. Mueller Hinton agar was prepared according to manufacturer's instructions and $20 \mathrm{ml}$ of the prepared medium was poured into petri dishes and allowed to solidify. The media were then inoculated (using the spread plate method) with the test organisms and labelled appropriately according to the test organisms and concentrations used $(40 \mathrm{mg} / \mathrm{ml})$. Wells were then made on the media with the aid of a sterile cork borer of $6 \mathrm{~mm}$ diameter after which $100 \mu \mathrm{l}$ of the prepared extracts was transferred into the wells in a drop-wise manner. In the same vein, $100 \mu 1$ of the standard antibiotics (ciprofloxacin and erythromycin $1 \mathrm{mg} / \mathrm{ml}$ each) was also transferred into the well as the positive control while $100 \mu 1$ of $20 \%$ DMSO was used as the negative control. The antimicrobial sensitivity test screening was done in triplicate and all the culture plates were next incubated at $37^{\circ} \mathrm{C}$ for $18-24 \mathrm{~h}$. The susceptibility of the test organisms to the plant extracts was indicated by clear zone of inhibition (IZ) around the wells containing the plant extracts and the diameter of the clear zones were taken as an index of the degree of sensitivity.

\subsection{Minimum Inhibitory Concentration (Mic) Test}

The MIC of Citrus peel extracts against the test organisms was determined using the standardized inoculum. The extracts concentrations was first prepared using a twofold serial dilution method. $400 \mathrm{mg}$ of the extract was dissolved in a test tube labelled A containing $4 \mathrm{ml}$ Mueller Hinton broth (this gives $100 \mathrm{mg} / \mathrm{ml}$ ), from test tube A, $2 \mathrm{ml}$ was transferred into a second test tube labelled B containing $2 \mathrm{ml}$ sterile Mueller Hinton broth (to obtain $50 \mathrm{mg} / \mathrm{ml}$ ). This process continued with concentrations of $25 \mathrm{mg} / \mathrm{ml}, 12.5 \mathrm{mg} / \mathrm{ml}, 6.25 \mathrm{mg} / \mathrm{ml}, 3.125 \mathrm{mg} / \mathrm{ml}, 1.56 \mathrm{mg} / \mathrm{ml}$ until the last concentration was prepared in a test tube labelled $\mathrm{H}$ (to give $0.781 \mathrm{mg} / \mathrm{ml}$ ) and $0.1 \mathrm{ml}$ of the standardized organism was added to each test tubes. Positive and negative controls were also mentained for each test batch of extract concentrations and test organisms (Akinyemi et al., 2006 and Kabir et al., 2005) i.e. sterile broth plus extract but without inoculation of the test organism for the negative control while for the positive control, sterile broth was inoculated with the test organisms but without the addition of the plant extracts. The test tubes were incubated at $37^{\circ} \mathrm{C}$ for $24 \mathrm{~h}$ in a shaker water bath, and the absorbance of each test tubes were red using Spectrophotometer at $600 \mathrm{~nm}$ wavelength while spectrophotometer was blanked using sterile Mueller Hinton broth void of extract and text organism. The MIC was determined by using the formula below in relation to the absorbance of the control.

$\mathbf{T}-\mathbf{C}_{\mathbf{0}}=\mathbf{C}_{1}$

The MIC is equal to the absorbance of the test concentration (T) with a significant reduction in absorbance after the subtraction of the absorbance of the negative control $\left(\mathrm{C}_{0}\right)$ and when compared with the absorbance of the positive control $\left(\mathrm{C}_{1}\right)$. 


\subsection{Minimum Bactericidal Concentration (MBC) Test}

The tube with no turbidity as compared to the control, which was regarded as the MIC together with other tubes higher in concentration than the MIC were sub cultured on to freshly prepared nutrient agar and the cultures were incubated at $37^{\circ} \mathrm{C}$ for $24-48 \mathrm{~h}$. The culture concentration without any visible growth after incubation was recorded as the $\mathrm{MBC}$.

\section{Statistical Analysis}

The results values obtained were expressed as mean \pm SEM (standard error of mean). Statistical analysis was performed using statistical package for social sciences (SPSS version 20) and one way analysis of variance (ANOVA) followed by Post Hoc multiple comparison and Duncan test to establish significance differences where $P$ values $<0.05$ was considered significant.

\section{RESUlTS AND DISCUSSION}

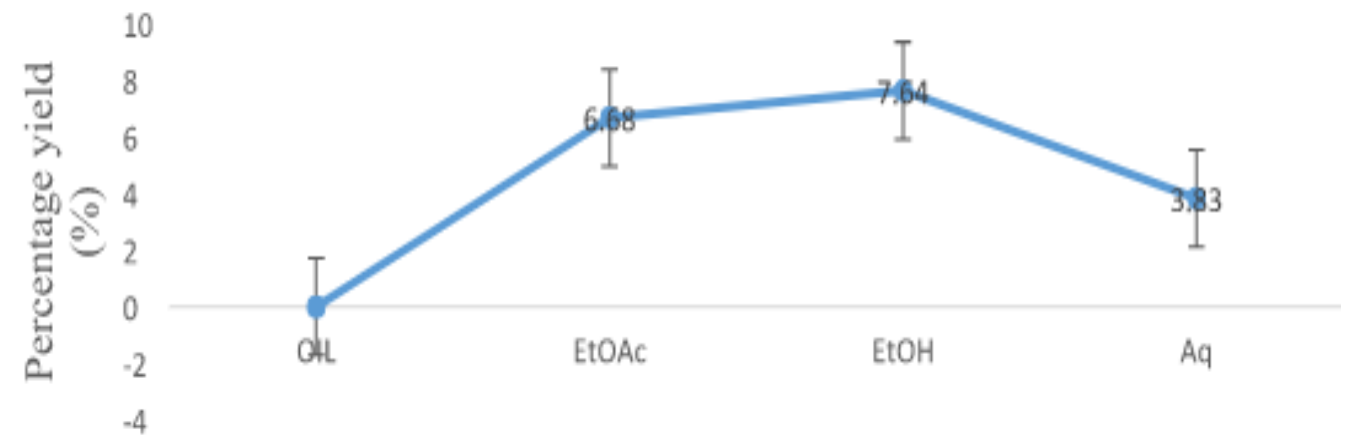

Fig1. Percentage yield of Citrus limon peel extract

Key: $E t O A c=$ ethyl acetate extract, $E t O H=$ ethanol extract, $A q=$ aqueous extract.

Table1. Identity of Test Organisms

\begin{tabular}{|l|c|l|l|l|l|l|l|}
\hline Test Organisms & $\begin{array}{l}\text { Grams } \\
\text { reaction }\end{array}$ & $\begin{array}{l}\text { Max } \\
\text { Score }\end{array}$ & $\begin{array}{l}\text { Total } \\
\text { Score }\end{array}$ & $\begin{array}{l}\text { Query } \\
\text { Cover }\end{array}$ & E & Identity & Accession \\
\hline $\begin{array}{l}\text { S.enterica subsp.enterica } \\
\text { serovar paratyphi A strain } \\
\text { SPA2 16s Ribosomal RNA gene } \\
\text { partial sequence. (1460bp) }\end{array}$ & - & 2697 & 2697 & $100 \%$ & 0.0 & $100 \%$ & KM977902.1 \\
\hline $\begin{array}{l}\text { S.enterica subsp.enterica } \\
\text { serovar paratyphi B strain 374 } \\
\text { 16s Ribosomal RNA gene } \\
\text { partial sequence.(1467bp) }\end{array}$ & - & 2676 & 2676 & $100 \%$ & 0.0 & $100 \%$ & JQ694526.1 \\
\hline $\begin{array}{l}\text { S.enterica subsp.enterica } \\
\text { serovar paratyphi C strain DT4 } \\
\text { 16s Ribosomal RNA gene partial } \\
\text { sequence. (1503bp) }\end{array}$ & - & 2776 & 2776 & $100 \%$ & 0.0 & $100 \%$ & JF951185.1 \\
\hline $\begin{array}{l}\text { S.enterica subsp.enterica } \\
\text { serovar typhi strain T4 16s } \\
\text { Ribosomal RNA gene partial } \\
\text { sequence. (1546) }\end{array}$ & - & 2856 & 2856 & $100 \%$ & 0.0 & $100 \%$ & EU118111.1 \\
\hline $\begin{array}{l}\text { Klebsiella pneumoniae strain } \\
\text { BYK-9 16s ribosomal RNA } \\
\text { gene partial sequence (1504bp) }\end{array}$ & - & 2778 & 2778 & $100 \%$ & 0.0 & $100 \%$ & KP255917.1 \\
\hline $\begin{array}{l}\text { Sreptococcus pneumoniae strain } \\
\text { ATCC 33400. 16s ribosomal } \\
\text { RNA gene partial sequence } \\
\text { (1515bp) }\end{array}$ & + & 2795 & 2795 & $100 \%$ & 0.0 & $100 \%$ & NR028665.1 \\
\hline $\begin{array}{l}\text { Sreptococcus pneumoniae strain } \\
\text { JCM 5674. 16s ribosomal RNA } \\
\text { gene partial sequence (1480bp). }\end{array}$ & + & 2734 & 2734 & $100 \%$ & 0.0 & $100 \%$ & LC071824.1 \\
\hline
\end{tabular}

Key: “.": Gram negative; “+”: Gram positive 
Therapeutic Potency of Citrus Limon (L) Burm. F. (Lemon) Peel Extract Against Some Disease Causing Microorganisms

Table2. Phytochemical Properties of Plant Oils, Peel, Juice and Leaf Crude Extracts

\begin{tabular}{|c|c|c|c|c|c|c|c|c|c|c|c|}
\hline $\begin{array}{l}\text { Plant } \\
\text { Extracts }\end{array}$ & Flavonoid & Phenols & Alkaloids & Tannins & Steroids & \begin{tabular}{|l|} 
Cardiac \\
gylcosides
\end{tabular} & Saponins & Terpenes & Volatile oil & anthraquinon & Resins \\
\hline EtOAc & + & + & + & + & + & + & - & + & + & + & + \\
\hline $\mathrm{EtOH}$ & + & + & + & + & + & + & + & + & + & + & \\
\hline $\mathrm{Aq}$ & + & + & + & + & + & - & + & + & + & - & + \\
\hline
\end{tabular}

Key: EtOAc: ethyl acetate extract, EtOH: ethanol extract, Aq: aqueous extract, (+): Present, (-): Absent

Table3. Mean Zones of Inhibition of Citrus Limon Peel extract ( $\mathrm{mm}$ )

\begin{tabular}{|l|l|l|l|l|l|l|}
\hline \multicolumn{9}{|c|}{ Plant extracts } \\
\hline Org & $\begin{array}{l}\text { EtOAc } \\
(40 \mathrm{mg} / \mathrm{ml})\end{array}$ & $\begin{array}{l}\text { EtOH } \\
(40 \mathrm{mg} / \mathrm{ml})\end{array}$ & $\begin{array}{l}\text { AqE } \\
(40 \mathrm{mg} / \mathrm{ml})\end{array}$ & $\begin{array}{l}\text { Cpx } \\
(1 \mathrm{mg} / \mathrm{ml})\end{array}$ & $\begin{array}{l}\mathrm{E}^{*} \\
(1 \mathrm{mg} / \mathrm{ml})\end{array}$ & $\begin{array}{l}\mathrm{D} \\
(100 \mu \mathrm{l})\end{array}$ \\
\hline SpA & $12.00 \pm 0.57^{\mathrm{e}}$ & $10.66 \pm 0.66^{\mathrm{ab}}$ & $8.33 \pm 0.33^{\mathrm{bc}}$ & $23.50 \pm 1.50^{\mathrm{a}}$ & $17.00 \pm 1.00^{\mathrm{bc}}$ & $0.00^{\mathrm{a}}$ \\
\hline SpB & $9.33 \pm 0.33^{\mathrm{bc}}$ & $12.00 \pm 0.57^{\mathrm{c}}$ & $7.66 \pm 0.33^{\mathrm{ab}}$ & $26.66 \pm 0.88^{\mathrm{a}}$ & $14.66 \pm 2.02^{\mathrm{ab}}$ & $0.00^{\mathrm{a}}$ \\
\hline SpC & $7.66 \pm 0.33^{\mathrm{a}}$ & $11.00 \pm 0.00^{\mathrm{c}}$ & $7.00 \pm 0.00^{\mathrm{a}}$ & $24.66 \pm 1.45^{\mathrm{a}}$ & $19.66 \pm 0.88^{\mathrm{c}}$ & $0.00^{\mathrm{a}}$ \\
\hline ST & $8.33 \pm 0.33^{\mathrm{ab}}$ & $10.00 \pm 0.00^{\mathrm{a}}$ & $7.00 \pm 0.00^{\mathrm{a}}$ & $25.33 \pm 0.33^{\mathrm{a}}$ & $12.00 \pm 1.00^{\mathrm{a}}$ & $0.00^{\mathrm{a}}$ \\
\hline Kp & $10.00 \pm 0.00^{\mathrm{cd}}$ & $10.00 \pm 0.00^{\mathrm{a}}$ & $9.00 \pm 0.57^{\mathrm{c}}$ & $25.66 \pm 0.88^{\mathrm{a}}$ & $17.66 \pm 0.33^{\mathrm{bc}}$ & $0.00^{\mathrm{a}}$ \\
\hline Sp & $11.00 \pm 0.57^{\mathrm{de}}$ & $11.66 \pm 0.33^{\mathrm{bc}}$ & $10.00 \pm 0.33^{\mathrm{d}}$ & $25.33 \pm 0.88^{\mathrm{a}}$ & $17.00 \pm 0.57^{\mathrm{bc}}$ & $0.00^{\mathrm{a}}$ \\
\hline Spy & $9.66 \pm 0.66^{\mathrm{bcd}}$ & $10.00 \pm 0.00^{\mathrm{abc}}$ & $12.00 \pm 0.00^{\mathrm{e}}$ & $30.00 \pm 1.00^{\mathrm{b}}$ & $20.0 \pm 0.33^{\mathrm{c}}$ & $0.00^{\mathrm{a}}$ \\
\hline
\end{tabular}

Key: Org: organism, Cpx: ciprofloxacin, E: erythromycin, D: dimethyl sulfoxide, SpA: Salmonella paratyphi A, SpB: Salmonella paratyphi B, SpC: Salmonella paratyphi C, ST: Salmonella typhi, Kp: Klebsiella pneumoniae, Sp: Stretococcus pneumoniae, Spy: Streptococcus pyogenes, NA: no activity.

*Specification for Cpx and $E: \leq 15^{R}, 16-20^{I}, \geq 21^{S}$ where $R$ is for resistance, I for intermediate and $S$ for susceptible (CLSI, 2012).

abcde: Values on the same column with different superscript are significantly different $(p<0.05)$.

Table4. Minimum Inhibitory and Bactericidal Concentration of Citrus limon Peel Extracts ( $\mathrm{mg} / \mathrm{ml})$

\begin{tabular}{|c|c|c|c|c|c|c|}
\hline & \multicolumn{2}{|c|}{ EtOAc } & \multicolumn{2}{c|}{ EtOH } & \multicolumn{2}{c|}{ Aq } \\
\hline Organisms & MIC & MBC & MIC & MBC & MIC & MBC \\
\hline SpA & 25 & 100 & 25 & 100 & 25 & 100 \\
\hline SpB & 25 & 100 & 12.5 & 50 & 25 & 50 \\
\hline SpC & 50 & $>100$ & 25 & 50 & 50 & $>100$ \\
\hline ST & 50 & $>100$ & 50 & 100 & 50 & $>100$ \\
\hline Kp & 25 & 100 & 12.5 & 50 & 25 & 50 \\
\hline Sp & 25 & 100 & 25 & 100 & 25 & 50 \\
\hline Spy & 12.5 & 50 & 25 & 50 & 25 & 50 \\
\hline
\end{tabular}

Key: SpA: Salmonella paratyphi A, SpB: Salmonella paratyphi B, SpC: Salmonella paratyphi C, ST: Salmonella Typhi, Kp: Klebsiella pneumoniae, Sp: Stretococcus pneumoniae, Spy: Streptococcus pyogenes; EtOAc: ethyl acetate extract, EtOH: ethanol extract, Aq: aqueous extract, Cpx: ciprofloxacin, E: erythromycin, D: dimethyl sulfoxide,

\section{DISCUSSION}

This research study is aimed at finding the therapeutic potency of Citrus limon peel extract against some disease causing organisms using the reflux extraction method, agar well diffusion and the tube dilution method for the antimicrobial susceptibility screening. The reflux extraction method was used in this study and four different solvent with different polarity index to obtain different compositions (Zarnowski, 2004). The advantages of using the reflux extraction method is the fact that there is displacement of transfer equilibrium by a repeated contact between the solvent and the solid matrix (the extract) and there is maintenance of a relatively moderate extraction temperature. Furthermore, this method requires simple and inexpensive equipment which is easy to operate (Luque de Castro, 1998).

The most widely-used solvent to extract edible oils from plant sources is hexane which has a fairly narrow boiling point range of approximately $63-69^{\circ} \mathrm{C}$ and it is an excellent oil solvent in terms of oil solubility and ease of recovery (Mamidipally, 2004). Ethanol was found to be more suitable for the extraction of the peel as more extract yield $(7.64 \%)$ was obtained with ethanol while ethyl acetate followed with yield of $6.68 \%$ and the lowest yield was obtained with water (3.83\%). There was no oil extract obtained (Figure 1). This result explains the fact that the constituents of the peel extract may 
be more soluble in ethanol than other solvents due to polarity differences. Furthermore, considering the method of extraction and the manner in which the solvents were applied (continous), shows that the extract may not be soluble in non-polar solvents and the more the polarity of the solvents increases, the more soluble it is. It is also not surprising that low yield was obtained with water owing to the fact that ethyl acetate and methanol must have extracted almost all of the polar constituents leaving few of them to be extracted by water. This is in conformity with the report of Sukhdev et al. (2008) on the Extraction Technologies for Medicinal and Aromatic Plants. It is important to explain a fact here that increase yield is not proportional to high antimicrobial activity. The activity of the extract depends on the availability of the active constituent and if the active constituent(s) is nonpolar, then a non-polar solvent is required for its extraction; though in some cases the activity may also depend on the amount of the active component. In this study, the non-polar solvent (n-hexane) did not yield any extract and two conditions might be responsible for this. First, the method of extraction (reflux) might not be suitable for its extraction (Sukhdev et al., 2008) and secondly it is possible that it was actually extracted but might be highly volatile such that if not well managed, it might have evaporated along with the solvent.

Eleven phytochemical constituents (saponins, alkaloids, flavonoids, anthraquinons, volatile oils, resins, phenols cardiac glycosides, tannins, terpenes, and steroids) were present in the peel extract (Table 2) and distributed among the different extract. The antimicrobial properties of medicinal plants have been attributed to the presence of phytochemicals in them notably tannins, flavonoids alkaloids etc. The applications of alkaloids are not limited to biological control of herbivores but also have pharmacological, veterinary and medical importance. Alkaloids belonging to beta-carboline group possess antimicrobial, anti-HIV and antiparasitic activities (Bouayad et al., 2011). The fact that akaloids possess therapeutic values does not rule out it negative effects in the human system when not well administered i.e. there are toxic alkaloids which may cause serious injury or even death as reported by Beyer et al. (2009); therefore toxicity test may be paramount in the quest for therapeutic plant extract. Flavonoids are of three sub-types and they include the bioflavonoids, isoflavonoids and the neoflavonoids (Galeotti et al., 2008). In plants, flavonoids have been found to be involved in UV filtration, symbiotic nitrogen fixation and floral pigmentation. They may also act as chemical messengers, physiological regulators, and cell cycle inhibitors. In addition, some flavonoids have been documented of its inhibitory activity against organisms that cause plant diseases, e.g. Fusarium oxysporum (Galeotti et al., 2008). In light of the above discussions, it is obvious that the activity of the plant peel extract may be tied to the availability of its phytoconstituents. The presence of secondary metabolites in medicinal plants may not necessarily guarantee its antimicrobial potency owing to the fact that there are different types and the presence of the active type may not be certain. A good example is the existence of different types of tannins such as the hydrolysable and the nonhydrolysable tannins in plant cells (Simon, 1993). The presence of these phytochemicals in the peel extracts could in no doubt be responsible for its antimicrobial activity. The result of the antimicrobial screening (Table 3 and Figure 2) shows that the peel has appreciable activity against the test organisms but the ethanol extract was more active compare to the ethyl acetate and aqueous extract. This is in conformity with the report of Amit et al. (2011) on the antimicrobial activity of selected citrus plant against some pathogenic microorganisms. The activity of the plant peel extracts were low when compared to the activity of the standard antibiotics (positive control), owing to the fact that the standard antibiotic is a pure substance. This also point to the fact that if further purification process is carried out on the crude peel extract, there is tendency that its activity will appreciate. Many factors have been seen to affect antimicrobial screening, one of which is the microorganism. This study result also shows that the test organisms reacted differently to the peel extract. While the Gram positive organisms were more susceptible, the Gram negative organisms were slightly resistant. In the same vein, the minimum inhibitory concentration test confirms that the Gram negative organisms may need higher concentration to achieve a greater effect as Salmonella paratyphi C and Salmonella typhi were the most resistant organisms recording MIC and $\mathrm{MBC}$ at $50 \mathrm{mg} / \mathrm{ml}$ and $100 \mathrm{mg} / \mathrm{ml}$ and in some cases the MBC were above $100 \mathrm{mg} / \mathrm{ml}$ (Table 4). MBC for S. paratyphi $C$ and $S$. typhi was above $100 \mathrm{mg} / \mathrm{ml}$ for ethyl acetate and aqueous extracts which suggest that higher concentrations is needed to completely kill these organisms or they might be biostatic in activity. In summary, the antimicrobial screening of the peel extract shows that the peel extract had activity against the test organisms but a higher concentration or dosage may be required to achieve a desired therapeutic threshold. Therefore, further analysis such as purification of the crude extracts and toxicity is recommended. 


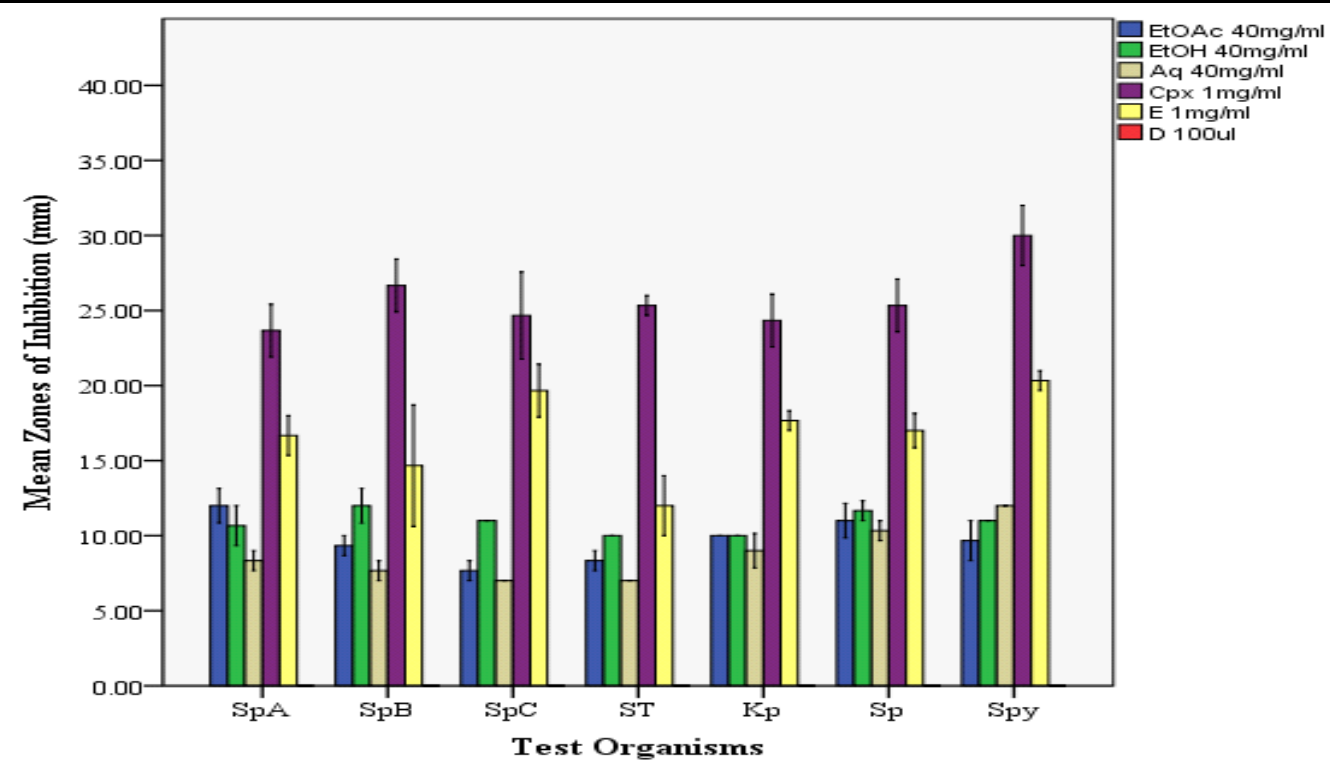

Fig2. Graphical representation of the Mean Zones of Inhibition of Citrus limon Peel extract (mm)

Key: Cpx: ciprofloxacin, E: erythromycin, D: dimethyl sulfoxide, SpA: Salmonella paratyphi A, SpB: Salmonella paratyphi B, SpC: Salmonella paratyphi C, ST: Salmonella typhi, Kp: Klebsiella pneumoniae, Sp: Stretococcus pneumoniae, Spy: Streptococcus pyogenes; EtOAc: ethyl acetate extract, EtOH: ethanol extract, Aq: aqueous extract, Cpx: ciprofloxacin, E: erythromycin, D: dimethyl sulfoxide.

\section{REFERENCES}

Abere, T. A., Okoto, P. E., Agoreyo, F. O. (2010). Antidiarrhoea and toxicological evaluation of the leaf extract of Dissotis rotundifolia Triana Melastomataceae. BMC Complement Altern Med 10: 71.

Agyare, C., Asase, A., Lechtenberg, M., Niehues, M., Deters, A., Hensel, A. (2009). An ethnopharmacological survey and in vitro confirmation of ethnopharmacological use of medicinal plants used for wound healing in Bosomtwi-Atwima-Kwanwoma area, Ghana. Journal of Ethno pharmacology 1253: 393-403.

Akinyemi, K. O., Oluwa, O. K and Omomigbehin, E. O. (2006). Antimicrobial activity of crude extracts of three medicinal plants used in south-west Nigerian folk medicine on some food borne bacterial pathogens. African Journal of Traditional Complementary and Alternative Medicines; 3 (4): $13-22$.

Amit, P., Arti, K., Sudeep, K, T. (2011). Evaluation of Antimicrobial Activity and Phytochemical Analysis of Citrus Limon, Journal of Pharmaceutical and Biomedical Sciences 13 (17). PP 1-7.

Beyer, J., Drummer, O and Maurer, H.H. (2009). Analysis of toxic alkaloids in body samples. Forensic Science International; 185(1-3):1-9.

Bouayad, N., Rharrabe, K., Lamhamdi, M., Nourouti, N.G and Sayah, F. (2011). Dietary effects of harmine, a $\beta$-carboline alkaloid, on development, energy reserves and amylase activity of Plodia interpunctella Hübner. Saudi Journal of Biological Sciences. 2011; 19(1):73-80.

Clinical and laboratory standard institute-CLSI. (2012). Performance standards for antimicrobial susceptibility testing; seventeenth information supplement (ed.), Vol 27(1); M100-S17.

Edeoga HO, Okwu DE, Mbaebie BO (2005). Phytochemical Constituents of Some Nigerian Medicinal Plants. African Journal of Biotechnology. 4 (7): 685-688.

Evans, J., Doyle, J., \& Delores, G. (2007). "Escherichia Coli". Medical Microbiology, 4th edition. The University of Texas Medical Branch at Galveston,

Galeotti, F., Barile, E., Curir, P., Dolci, M and Lanzotti, V. (2008). "Flavonoids from carnation (Dianthus caryophyllus) and their antifungal activity". Phytochemistry Letters 1: 44-48.

Jitu, B., Konwar, B. K. \& Bordoloi, M. J. (2011). Der Pharmacia Sinica, 2 (6), 149-152.

Jonas, W., Kaptehuk, T., \& Linde, K. (2003). A critical overview of homeopathy. Annals of Internal Medicine, 138, pp 393-39. 
Kabir, O. A., Olukayode, O., Chidi, E. O., Christopher, C. I and Kehinde, A. F. (2005). Screening of crude extracts of six medicinal plants used in South-West Nigerian unorthodox medicine for anti-methicillin resistant Staphylococcus aureus activity. BMC Complementary and Alternative Medicine, 5 (6): 1-7.

Luque de Castro, M.D. \& Garcia-Ayuso, L.E. (1998). Soxhlet extraction of solid materials: An outdated technique with a promising innovative future. Analytica Chimica Acta. 369, 1-10.

Mamidipally, P.K., \& Liu, S.X. (2004). First approach on rice bran oil extraction using limonene. European Journal of Lipid Science and Technology. 106, 122-125.

Plant Database. (2008). National Plant Database Ceter Stapf. USDA, NRCS.The plant Database. http://plants.usda.gov. Los Angeles 70874-4490 USA.

Rios, J. L., \& Recio, M.C. (2005). Medicinal plants and antimicrobial activity. Journal of Ethnopharmacology 100: 80-84.

Shivendu, R., Nandita, D., Proud, S., Madhumita, R and Ramalingam, C. (2012). Advances in Applied Science Research, 3 (1):495-501.

Simon, M. (1993). "The Systematic Distribution of Tannins in the Leaves of Angiosperms: A Tool for Ecological Studies". Journal of Biochemical Systematics and Ecology 21 (8): 833-846.

Sofowora, E. A. (2003). Medicinal plants and Traditional medicine in Africa. John Wiley and sons Ltd, New York. 256-257.

Sukhdev S.H., Suman, P. S. K., Gennaro, L and Dev, D. R. (2008). Extraction Technologies for Medicinal and Aromatic Plants International. Centre for Science and High Technology, Trieste ed, pp 11.

Trease, G. E., and Evans, W. C (2002). Pharmacognosy. $11^{\text {th }}$ ed. Bailliere Tindll., London. Pytochemistry: Introduction in General Methods, 227-247.

United Nations Educational, Scientific and Cultural Organisation. (1994). Traditional knowledge into the twenty-first century, Nature \& Resources, Volume 30,N02, UNESCO, Paris.

Zarnowski, R., \& Suzuki, Y. (2004). Expedient Soxhlet extraction of resorcinolic lipids from wheat grains. Journal of Food Composition and Analysis, 17, 649-664. 